\title{
Woman-centred care in childbirth: A concept analysis (Part 1)
}

\author{
Authors: \\ Maria S. Maputle ${ }^{1}$ \\ Hiss Donavon ${ }^{2}$ \\ Affiliations: \\ ${ }^{1}$ Department of Advanced \\ Nursing Science, University \\ of Venda, South Africa \\ ${ }^{2}$ Department of Medical \\ Biosciences, University of the \\ Western Cape, South Africa

\section{Correspondence to:} \\ Maria Maputle \\ Email: \\ sonto.maputle@univen.ac.za \\ Postal Address: \\ Private Bag X5050 \\ Thohoyandou 0950, \\ South Africa \\ Dates: \\ Received: 25 Aug. 2011 \\ Accepted: 10 Aug. 2012 \\ Published: 27 May 2013 \\ How to cite this article: \\ Maputle, M.S. \& Hiss D., \\ 2013, 'Woman-centred care \\ in childbirth: A concept \\ analysis (Part1)', Curationis \\ 36(1), Art. \#49, 8 pages. \\ http://dx.doi.org/10.4102/ \\ curationis.v36i1.49
}

Read online:
'Woman-centred care' in childbirth is a process in which a woman makes choices and is involved in and has control over her care and relationship with her midwife. The aim of this paper is to study the concept of woman-centred care through analysis in the context of childbirth. The attributes, antecedents and consequences of this concept are identified, and a model case, a borderline case and a contrary case constructed to achieve conceptual clarity. A concept analysis was undertaken as described by Walker and Avant (2011), with an extensive exploration of domain-specific literature and evidence from various disciplines.

It was established from the concept analysis that 'woman-centred care' was complex and experienced individualistically. The analysis indicated that mothers' participation is supposed to be based on a more collaborative relationship and partnership. Participation is exhibited by open communication and the mother's involvement in decision-making, consultation and collaboration with the attending midwife, further characterised by mutual respect and the midwife listening to the mother's views. There is also an exchange of complete and unbiased information, recognition and honouring of cultural diversity and making of informed choices. Through an inductive discovery approach and drawing on inferences, attributes were clustered in an attempt to identify the apparent essence of the concept.

From the results of the concept analysis described in this study, the researchers recommend the formulation of criteria that could facilitate implementation and evaluation of womancentred care and its empirical referents in the context of the Batho Pele principles (Part 2).

\section{Introduction}

A concept can express the same idea, in various sets of words (Tofthagen \& Fagerstrom 2010:21). The aim of concept analysis is to clarify meanings of similarity and identify multiple considerations for measuring the concept (Falan 2010:143). Concept clarification is an important step in developing useful and usable knowledge in childbirth. In this article concept analysis was conducted subsequent to research undertaken in the tertiary academic hospital complex of the Capricorn district in Limpopo Province, that determined experiences of childbirth of mothers (Maputle \& Nolte 2008) and their attending midwives (Maputle \& Hiss 2010).

A qualitative exploratory, descriptive, contextual and inductive research approach was followed. The sample consisted of 24 mothers and 12 attending midwives. Different data collection methods were used. Data obtained from unstructured in-depth interviews were analysed according to the protocol by Tesch (1990, cited in Creswell 2003:155). Data analysis from participant observations using a semi-structured approach and visual analogue scale was performed quantitatively using frequency distribution.

After a description of the experiences of mothers and attending midwives of childbirth, a synthesis of the results from the empirical data, supported by a literature control, revealed the core category as 'woman-centred care'. The research was conducted in four phases: phase 1 - empirical, phase 2 - concept analyses (which this paper addresses), phase 3 - model development, and phase 4 model validation.

\section{Problem statement}

A synthesis of results from empirical data on the experiences of mothers and attending midwives of childbirth, as supported by a literature control, revealed the core category as 'woman-centred care'. The concept 'woman-centred care' has frequently been used in literature; however, there is no consensus about its meaning and its use in childbirth. This article used Walker and Avant's $(2005 ; 2011)$ method of concept analysis as a framework to analyse woman-centred care. 


\section{Background}

The situation in hospitals that provide childbirth care is such that prescribed routines are adhered to frequently, as laid down in the policies and procedures which are strategically placed in the ward. Midwives generally regard it as their responsibility to ensure that the rules are adhered to. Pearson, Vaughan and Fitzgerald (1998:34) indicate that the end results of such an approach are standardised routines for mother care during childbirth. They further point out that mothers are often expected to comply with a predictable pattern and follow the routine laid down by the regulations. Adherence to such standardised routines may have substantial merit, but when followed without skilled assessment pose a significant risk of depersonalising mothers and discouraging their full participation and involvement during midwifery care.

Standardised routines can also be viewed as part of the biomedical model, which has a dominant effect on health care as it serves mainly the relevance of midwives to their public roles during childbirth. The biomedical model is characterised by a concentration of information and decisionmaking in the hands of doctors and midwives, and to a lesser extent in those of women. The emphasis of the model is more on high technology, that leads to the loss of basic human care. Women are labelled according to their diagnoses, rather than being recognised as patients with needs that call for appropriate attention and responsiveness. Nevertheless, Pearson et al. (1998:37) affirm that the biomedical model is well developed and undoubtedly gives indispensible direction to midwifery practice.

It is not surprising that pressure from society coupled with increased understanding of human nature through the Patients' Rights Charter and Batho Pele principles have highlighted the restrictive nature of the biomedical model, the alternative approach being the provision of 'womancentred care'. The Batho Pele principles seek to introduce and orient midwives towards a customer-focused approach that will improve systems, procedures, attitudes and behaviour within childbirth units (Department of Public Service and Administration 1997). The White Paper aptly indicated that this did not necessarily mean introducing more rules and centralised processes, or micro-managing service delivery activities. Rather, it involved creating a framework for delivery of public services which treated citizens more like customers and enabled them to hold public servants to account for the services they rendered.

The White Paper on the Transforming of Service Delivery (Department of Public Service and Administration 1997) through the eight Batho Pele principles (consultation, service standard, courtesy, access, information, openness and transparency, redress, and value for money) aims to overhaul the entire standard of the public service and encourage effective service delivery. Services should be based on a customer-orientated framework. These principles were integrated within the context of the concept 'womancentred care' (Table 1). The Department of Public Service and Administration (1997) indicates that the importance of public service delivery lies in the need to build confidence and trust between the provider (midwife) and the user (mother) through openness and transparency. Sandall (1995:201) and Midmer (1992:216) support the notion of customer-oriented service delivery, arguing that the philosophy and focus should shift from technologisation to personalisation, and to building a paradigm of 'woman-centred practice' based on equal partnership between mothers and attending midwives.

\section{Aim of the study}

The aim of the study was to conduct concept analysis of woman-centred childbirth care in order to clarify meanings of similarity and identify multiple considerations for measuring the concept. Hence the research question addressed in this article is: What is the meaning of woman-centred care in childbirth?

\section{Research design and methods Research design}

An inductive-discovery approach that focused on identification of relevant aspects of the concept was used, as the researchers sought to identify what is common in the use of the concept (Rodgers 1993:79). A concept analysis was conducted in order to obtain the operational definition and to define attributes, antecedents and consequences of the concept 'woman-centred care'. In addition, a model case, a borderline case and a contrary case were constructed to achieve conceptual clarity (Malusky 2005:28; Sun \& Knobf 2008:334).

Concept analysis is used to examine and describe a concept and its application. The objective is to understand what the concept is about (Walker \& Avant 1988, cited in Walker \& Avant 2005:63,84). The concept should be clear and distinct, unambiguously defined and well differentiated from other concepts, and should be applicable to the world and appropriate to the context (Chabeli \& Muller 2004:38). Concept analysis is applied for the refinement and definition of concepts originating from nursing practice, nursing research and nursing theory (Falan 2010:146). This would facilitate

TABLE 1: Batho Pele principles integrated within the context of the concept 'woman-centred care'.

\begin{tabular}{ll}
\hline Services & Principles \\
\hline Consultation & $\begin{array}{l}\text { Midwives should consult mothers about the level of midwifery care they want to receive and, where possible, allow involvement and support } \\
\text { choices about the services that are offered. }\end{array}$ \\
$\begin{array}{l}\text { Service standard } \\
\text { Courtesy }\end{array}$ & Mothers should be told what level and quality of midwifery care (interventions) can be provided, so that they should be aware of what to expect. \\
Access & Mothers should to be treated with courtesy and consideration, that is, they should be allowed to practice their preferences during childbirth. \\
Information & Mothers should be given full and accurate information about the childbirth process and midwifery care to which they are entitled. \\
\hline
\end{tabular}


differentiation between similar and dissimilar concepts. Walker and Avant (2005:63-84) assert that concept analysis and development are fundamental processes required by nurse researchers who are attempting to measure the metaphysical phenomena of nursing (midwifery) practice. They further state that by definition, concept analysis is a process of operationalising a phenomenon so that it can be used for theory development and/or research measurement. They implied, thus, that a scientifically developed concept is the essential first step in any research process. Concepts are viewed as the building blocks with which theory can be constructed, and their analysis is considered essential if the concepts are to be actively and correctly operationalised (Eustace \& Ilagan 2010:2095; Mikkelsen \& Frederiksen 2011:1154). Walker and Avant (2011;2005:63-84) were leading pioneers in adapting theoretical work related to concepts for the discipline of nursing. They based their process on the work of Wilson (1963, cited in Walker \& Avant 1995), truncating the 13 steps into eight basic elements, which included selection of an appropriate concept through development of model cases, and to identification of 'empirical referents'.

\section{Methods: Concept analysis}

The framework suggested by Walker and Avant (2005:63-84) was used for the analysis described in this research. The method included:

- selection of the concept

- specification of the aims of analysis

- identification of uses, characteristics or connotations of the concept

- determination and definition of attributes

- development of model cases which exemplify the analysis

- identification of antecedents and consequences

- definition of empirical referents.

A study 'Experiences of childbirth by mothers at the tertiary hospital in Limpopo Province' was conducted (Maputle \& Nolte 2008), and experiences of the mothers during childbirth revealed the major concept 'woman-centred care'. 'Womancentred care' emerged as a core concept because it was found to be the central idea or event, and all the other categories and attributes were contingent upon it. The concept was also relevant to childbirth care within the framework of the Batho Pele principles directed at a customer-focused approach. An extensive literature search of computerised databases and manual searches of online journals were also undertaken to ensure that characteristics associated with the concept of woman-centred care were included in the search terms. Literature-based analysis included specific disciplines, for example nursing, medicine, humanities and nursing management.

\section{Aims of analysis}

In the process of analysis the characteristics of the concept and surrogate terms were identified and the related concepts, antecedents and consequences were documented. The researcher used all the steps outlined in Walker and Avant
(2005:63-84). An extensive literature search was conducted to achieve the aims of analysis. The main aim of the analysis was to offer a medium for identifying the shared meaning of imaginative concepts. It further explored the use of the concept 'woman-centred care' within the context of childbirth units. The critical attributes of 'woman-centred care' as both process and product had to be identified, and differences between 'woman-centred care' and 'midwifecentred care' distinguished. The analysis determined the meaning of the concept 'woman-centred care' and its usefulness, applicability and effectiveness as a key concept in childbirth. Moreover, concept analysis was used to define a term for subsequent research or to examine how a concept was used within the current literature or in actual clinical practice (Chinn \& Kramer 1995:81).

\section{Identification of uses, characteristics or connotations of the concept}

To accomplish identification of the uses, characteristics or connotations of the concept, a dictionary and the impressions of colleagues and available literature on the subject were used. Unsworth (2000) affirms that dictionary definitions are authentic and therefore useful because they convey accepted ways in which words are used. This paradigm can be useful in defining the scope of any subsequent analysis of the literature. The woman is part of the family. However, the concept of 'woman-centred care' is frequently not welldefined in dictionaries. The concept analysis of Hutchfield (1999:91) was adopted to define the use of family-centred care (woman-centred care). This definition suggested that familycentred care (woman-centred care) was a holistic approach, with professionals and family working collaboratively towards a common outcome. The opportunity was thus given to the family members to care for their relative (during childbirth). The collaboration allowed independence and the possibility of co-opting the family into the plan of care. Family-centred care was firmly entrenched in respect for and cooperation with the family.

According to this view, the nurse was an equal partner and a facilitator of care. The empowerment of women during childbirth is possible, but may need to be conceptualised differently from family-centred care. It was thus proposed that woman-centred care shifted the emphasis to the mother as the key figure in childbirth, and granted her the mandate to personalise her childbirth to suit both her needs and those of her family. In childbirth, for example, the concept 'womancentred care' was used in relation to mutual participation and interdependent collaboration. According to Hutchfield (1999:90), the literature gathered focus on identifying the essential nature or 'essence' of the concept in the form of attributes. The attributes are not dictionary definitions, but represent the 'real definition of the concept'.

'Woman-centred care' is a core concept that refers to involving the woman in treatment decisions, increasing communication between the midwife and woman towards an understanding of what to expect from treatment plans, 
recovery and aftercare (Bechell, Myers \& Smith 2000:402). Johnson, et al. (2003:30) refer to 'woman-centred care' as a process in which a woman makes choices, and is involved in and has control over her care and relationship with her attending midwife. Likewise, 'woman-centred care' encourages the mother to articulate her ideas and views. As partners, the mother and the midwife take the mother's emotional and social environment into account and require mutual participation (Anderson 2002:80).

'Woman-centred care', according to Rush (1997), cited in Hutchfield (1999:94), refers to a complex, multidimensional, dynamic process of providing safe, skilled and individualised care. It responds to the physical, emotional and psychosocial needs of the mother. However, 'woman-centred care' as outlined within the context of the Batho Pele principles in the White Paper on Transforming Public Service Delivery (Department of Public Service and Administration 1997), is customer-oriented care, in the following manner: a midwife consults the mother, encourages her involvement and supports her choices about the services offered. A mother is allowed to practice preferences (courtesy), with equal access to personal control and decision-making (access). Moreover, a mother is given full and accurate information about childbirth and the midwifery care to which she is entitled. Unsworth (2000:65) refers to 'woman-centred care' as the sum of activities that includes emotional involvement, responsible participation and a sharing of practical and technical knowledge of health care.

\section{Connotations of 'woman-centred care' that emerged from the literature}

In this study 'woman-centred care' was seen as a philosophy of care that brought about mutual participation and the involvement of both the mother and the attending midwife. However, Nethercott (1993), cited in Hutchfield (1999:90), identifies the differences between a mother's involvement and participation. Involvement is seen as an antecedent of woman-centred care in which the attending midwife exercises control over the mother's involvement, whereas a mother's participation is supposed to be based on a more collaborative relationship and partnership. Participation in the study exhibited open communication, the mother's involvement in decision-making, consultation and collaboration between the mother and the attending midwife, further characterised by mutual respect and the midwife listening to the mother's views. There was also an exchange of complete and unbiased information, recognition and honouring of cultural diversity and making of informed choices. However, such a list of connotations does not clarify the concept. Hutchfield (1999:90) states that analysing the components of the whole and sorting them into categories makes the concept more understandable.

\section{Determination of defining attributes}

The meanings of the concept identified above determine ithe attributes and essential characteristics of the it. The components that constitute the concept should be applicable to any situation in which the concept is located. Walker and Avant (2005:63-84) suggest that the characteristics that occur most frequently during concept analysis become the defining attributes. They further point out that this is arbitrary and in many cases there is no account of how the attributes were identified. They continue to suggest that there are three debatable criteria for defining attributes, '(1) characteristics that occur frequently in literature, (2) characteristics that are the equivalent of necessary conditions and (3) purity, as in what the defining attributes are trying to achieve.

The characteristics that surfaced in this analysis of 'womancentred care' were those that occurred frequently, that were deemed necessary 'during childbirth', and together gave a holistic picture of 'woman-centred care'. However, as Gould (2000), cited in Walker and Avant (1995:41), also states, it is acknowledged that there is the potential for personal bias as the author has the power of selection. Therefore it would be useful to discuss the aspect of selection and further discarding of attributes.

The interaction and experience is unique for both the individual mother and the midwife. Therefore dictionary definitions such as 'typical', 'usual' and 'average' are not robustly applicable to a working definition of 'womancentred care'. Mutual participation and information-sharing as definitions of 'woman-centred care' are regarded as prerequisites and as such are an antecedent and also a necessary consequence of 'woman-centred care'. Defining attributes are criteria which help differentiate the concept from a related one. Walker and Avant (1995:41) and Ellis-Stoll and Popkess-Vawter (1998:65) describe defining attributes as the characteristics of a concept that appear repeatedly.

In the foregoing definition of 'woman-centred care' the essential attributes determined from research findings as experiences of childbirth by mothers and of managing mothers during childbirth by attending midwives, were mutual participation and responsibility sharing, information sharing and empowering, interdependence and collaboration, participative decision-making, open communication and listening, respect and accommodative midwifery actions, selfdetermination and self-reliance, as well as the maximisation of human and material infrastructure. The interaction is dependent upon mutual participation, with interdependent and collaborative actions of both the mother and attending midwife during childbirth.

An analysis of the literature presented the connotations ascribed to 'woman-centred care' during childbirth. 'Woman-centred care' was assessed in its optimal sense for the purposes of establishing critical attributes, model case development and the determination of antecedents and consequences. The essential attributes of 'woman-centred care' during childbirth, as determined from the data, are therefore as follows:

- Mutual participation and responsibility sharing, as evidenced by interdependent collaboration, co-operation and consultation between the mother and the attending midwife during childbirth. 
- Information sharing and empowering by virtue of exchange of complete and unbiased information that will facilitate participation in informed decision-making and informed choices, and promote the mother's functioning and autonomy.

- Communication and listening by means of a relationship that is non-judgemental and based on honest and open communication, respect and listening to the mother's views.

- Accommodative midwifery actions through recognition and honouring of cultural sensitivity and the support of choices.Maximising human and material resources, as borne out by adequate, competent staff to render midwifery care and the provision of privacy, and the presence of a companion during childbirth.

These critical attributes provide a more comprehensive view of 'woman-centred care' during childbirth, the focus of which was on the positive aspects of 'woman-centred care' during childbirth. The existence of these attributes reinforces woman-centred care during childbirth.

\section{Development of model cases}

A model case is a 'real-life' example of concept usage, in which all the critical attributes are present (Mentro, Steward \& Garvin 2002:60; Walker \& Avant 1995:42). The following is a model case of 'woman-centred care' based on the observations of the researchers.

Lindy, aged 21 years, was pregnant for the first time. She was Venda-speaking and the midwife was a Northern Sotho-speaking woman. Lindy was in active labour and was admitted to the ward at 20h00. According to her antenatal clinic record, Lindy had attended the clinic four times and was actively participating in her care. When asked about her experiences of childbirth regarding mutual participation, Lindy said:

'Yes, I felt I participated in my care because I had a prolonged labour and I told the sister that I can't take it any longer and I won't deliver and they must insert me a drip and take me to the operation. Indeed, she called the doctor who examined me and I was done an operation. ... To me midwives were Ok ... because they were allowing me to be up and about as I preferred.'

Participation requires a mutual, egalitarian and respectful relationship. Equality includes the principle of sharing power and responsibility. There was room for negotiation between Lindy and the midwife. Lindy was participating in her care because she had sufficient information that had been provided by the midwife, which is a prerequisite for decisionmaking. 'Woman-centred care' promoted interaction between Lindy and the midwife, and this enhanced Lindy's self-esteem and self-determination. The midwife and Lindy listened to each other because they engaged in a dialogue to identify preferences and expectations, and a new or changed strategy for 'woman-centred care' was constructed. The model case included all the critical, defining attributes of 'woman-centred care' during childbirth.

\section{Identification of alternative cases}

Alternative cases are identified to provide examples of what the concept is not, as this often aids clarification of the concept (McKenna 1997, cited in Walker \& Avant, 2005:6384). Alternative cases include contrary cases, which have characteristics that clearly do not represent the concept. These include related cases, which demonstrate instances that are similar to the concept, but on closer examination are quite different; borderline cases, which are very similar to the model case, but some of the defining attributes are missing; invented cases, which are evidently invented in an out-ofthe-ordinary situation; and illegitimate cases, in which the concept is located in a real-life scenario, but out of context of the defining attributes (Chinn \& Kramer 1995; Walker \& Avant 1995).

The only alternative case described is a contrary case. Development of this type of case, rather than another, provides clearer recognition of the defining attributes of 'woman-centred care'. In this example Joyce, aged 19 years, was pregnant for the first time. She was Tsonga-speaking and the midwife was a Northern Sotho-speaking woman. Joyce was in active labour and was admitted to the ward at $23 \mathrm{~h} 00$. According to her antenatal care record Joyce had attended the clinic only twice. She had limited information regarding childbirth issues and an awareness of available options. She was disempowered and lacked autonomy in childbirth care. The midwife was telling her what to do and how to behave throughout labour. When asked about her experiences of childbirth, Joyce said:

'Midwives know what to do and how to care for us during labour, but at times I just felt I'm not involved because I'm just told what to do without being asked. I don't want to be restricted; I wanted to be up and about alternating with resting.'

There was inadequate participation, limited decisionmaking scope and practices that fostered dependency and a prevailing authoritative approach within the childbirth unit. The strict routines laid down by the regulations seemed to depersonalise Joyce, resulting in her non-participation. The midwife imposed her authority and responsibility to ensure that rules were adhered to. Joyce was merely seen as the one who should comply with the rules of the unit, with no power of decision. There was also over-reliance on technology. Throughout labour there was a language barrier between Joyce and her midwife. When asked, Joyce said: 'I didn't clearly understand her language so I was just keeping quiet during childbirth'.

Ineffective communication, for example inadequate listening skills by a midwife and existence of a language barrier between the mother and midwife, often result in limited participation. The midwife-centred care approach seemed to limit the physiological processes, and the psychosocial aspects of the mother were thus ignored. This contrary case clearly demonstrates what 'woman-centred care' is not. Joyce was denied an opportunity for mutual participation, empowerment and information sharing during childbirth. Apart from the fact that Joyce did not participate as she 
wished to during labour, she also experienced a language barrier and ineffective communication between herself and the midwife.

\section{Identification of antecedents and consequences}

Identifying antecedents and consequences aids clarification of the defining attributes and the context in which they occur (Figure 1). Antecedents must be in place for the concept to occur (McKenna 1997, cited in Walker \& Avant 2005:63-84). In order for the concept of 'woman-centred care' to occur, there should be mutual and collaborative interaction between the mother and her attending midwife. The mother should be consulted, respected and informed about the services that are available to her during childbirth.

It is acknowledged that these consequences are not exclusive to 'woman-centred care'. For example, it could be argued that they could apply equally to all mothers in the childbirth unit, whether participation was promoted or not. Walker and Avant (1995:45) define antecedents as events or incidents that must happen prior to the occurrence of the concept. Likewise, consequences are circumstances resulting from occurrence of the concept (Walker \& Avant 1995:45). An examination of the antecedents and consequences of 'woman-centred care' allows further refinement of the critical attributes, thus facilitating the formulation of criteria for woman-centred care.

\section{Antecedents}

Antecedents are events that must be present before the occurrence of the concept. Analysis indicated that antecedents of efficient 'woman-centred care' should be based on mutual participation and collaboration, open communication and listening, respect and honouring of cultural sensitivity, as well as information sharing which leads to informed

- Interdependent collaboration

- Participative decision-making

- Promote functioning, informed choices and autonomy

- Open communication and respect

- Recognising and honouring cultural sensitivity (accommodative)

- Adequate, competent staff and provision of privacy and companion Antecedents

- Mutual participation and responsibility sharing

- Information sharing and empowering

- Open communication and listening

- Accommodative midwifery actions

- Maximise human and material infrastructure Defining attributes

- Mutual participation and egalitarian relationship
- Equality with principle of power and responsibility sharing

- Equality with principle of power and responsibility

- Well-informed to enhance self-esteem, self-reliance and self-determination - Independence

Consequences decision-making, choices and autonomy. There should be adequate and competent staff to provide midwifery care during childbirth. These are necessary conditions that must be satisfied before 'woman-centred care' can be accomplished during childbirth.

Richter et al. (2001:174) are of the view that participative decision-making requires patients to be knowledgeable about their health care with the ability to process medical information and understand the outcomes of the choices they make. If any of these conditions are not met, significant alterations in the mother's and midwife's mutual participation and collaboration might occur, thus interfering with the provision of 'woman-centred care'. Since 'womancentred care' is viewed as part of a reciprocal process, it is essential that a midwife who is consistently sensitive to the mother's needs be present. Furthermore, if there is limited participation and collaboration, then a lack of participation and informed decision-making will result from the mother. This may indicate an inability to meet the needs of the mother on the part of the midwife. Such a lack of participation may also decrease patient satisfaction with the outcome (Richter et al. 2001:174).

\section{Consequences}

Consequences are incidents that emerge as a result of the concept. Some of the consequences of 'woman-centred care' are highlighted as the critical attributes of the concept, and are corroborated by Pelkonen, Perala and VehvilainenJulknnen (1998:22):

- mutual participation, and an egalitarian and respectful relationship

- equality, with the principles of power and responsibility sharing

- partnership and collaboration in decision-making

- being well informed to enhance self-esteem and selfdetermination

- interdependence.

If efficient woman-centred care occurs, mutual participation will be obvious and mothers will participate in their care.

\section{Defining empirical referents}

The final step of the analysis is to identify the empirical referents or indicators used to measure the concept or validate its existence in reality (Walker \& Avant 1995). These can also be referred to as measurable properties that further verify the concept. Empirical referents are defined as classes or categories of actual phenomena that by their existence or presence demonstrate the occurrence of the concept itself (Walker \& Avant 1995:46). The defining empirical referents of 'woman-centred care' were measured through use of the customer-care approach and Batho Pele principles. The principles of Batho Pele chosen were consultation, service standards, courtesy, access and information.

The empirical attributes of 'woman-centred care' in this article were mutual participation and responsibility sharing; 
information sharing and empowering; communication and listening; accommodative midwifery actions; and maximising human and material infrastructure. Each of these referents were integrated within the Batho Pele principles and measured by the formulated criteria (Part 2).

The construction of referents operationalised the concept of interest. Walker and Avant (1995:46) state that once identified, referents are extremely useful in instrument development, because they are clearly linked to the theoretical base of a concept, thus contributing to both the content and construction of the instrument. As such they provide clear and observable phenomena of the concept. Furthermore, instrument development in itself is an operational definition (Burns \& Grove 2003:147).

From the results of concept analysis in this study the researchers formulated criteria for the implementation of 'woman-centred care' that were integrated into the Batho Pele principles in order to measure these empirical referents.

\section{Trustworthiness}

The criteria for ensuring trustworthiness as outlined in Guba and Lincoln (1985:301-318) were used. Peer debriefing through discussion with peers who are outside the context and have a general understanding was used. Presentations at research committees and seminars were attended to establish the truth-value of concept analysis. Transferability was attained through thick description of the methodology.

\section{Ethical considerations}

Ethical approval to conduct the study was obtained from the Ethics Committee of the University of Johannesburg and permission from the Limpopo Provincial Department of Health. The ethical standards as set by the Democratic Nursing Organisation of South Africa (DENOSA) were adhered to before and during the unstructured interview sessions regarding privacy, anonymity and confidentiality (DENOSA 1998).

\section{Limitations}

The concept of 'woman-centred care' is often not well-defined in dictionaries. Empirical investigation has been conducted to clarify the concept, as lack of investigation may result in certain limitations in the methodology of concept analysis.

\section{Recommendations}

In terms of practice, it is recommended that the empirical referents of 'woman-centred care' be integrated into Batho Pele principles to measure the concept. When the empirical referents of the concept are understood, mutual participation during childbirth will be enhanced. With regard to implications for theory development, it is recommended that a model of 'woman-centred care' in childbirth be developed based on the results of the concept analysis. For nursing education, the empirical concept analysis would assist learners to acquire an interactive constructing process followed by consolidation of knowledge, creating new insights for critical thinking.

\section{Conclusion}

Concept analysis is a part of knowledge development. Clarified concepts may be applied to midwifery situations. They provide an illuminating insight into problems which, in turn, motivate further analyses. Challenges in the childbirth units demanded the use of 'woman-centred care' in order to facilitate and promote mutual participation of women during childbirth. The concept would foster mutual participation, and an egalitarian and respectful relationship. There would be partnership and collaboration in decision-making between the attending midwife and a woman during childbirth.

\section{Acknowledgements Competing interests}

We declare that we have no financial or personal relationship which has influenced us in writing this paper.

\section{Authors' contributions}

M.S. (University of Venda) and H.D. (University of the Western Cape) were involved in conceptualisation of the project. M.S. collected and analysed data and H.D. wrote and edited the manuscript.

\section{References}

Anderson, E.B., 2002, 'Patient-centeredness: A New Approach', viewed 18 July 2009, from http://www.ncbi.nlm.nih.gov/entrez

Bechell, D., Myers, W. \& Smith, D., 2000, 'Does patient-centred care pay off?', Journal on Quality Improvements 26(7), 400-409.

Burns, N. \& Grove, S.K., 2009, The practice of nursing research: Appraisal, Synthesis, Generation of Evidence, 6th edn., Saunders Elsevier, St Louis, MO.

Chabeli, M. \& Muller, M., 2004, 'Reflective thinking in clinical nursing education: a concept analysis', Curationis 27(4), 49-62.

Chinn, P.L. \& Kramer, M.K., 1995, 'Theory and nursing: A systematic approach. Mosby, New York.

Creswell, J.W., 2003, Research Design: Qualitative and Quantitative approaches. Thousand Oaks, Sage Publishers.

Democratic Nursing Organisation of South Africa, 1998, Position Statement, Democratic Nursing Organisation of South Africa, Pretoria.

Department of Public Service and Administration, 1997, People First: White Paper on Transforming Public Service Delivery, Department of Public Services and Administration, Pretoria.

Ellis-Stoll, C.C. \& Popkess-Vawter, S., 1998, 'A concept analysis on the process of empowerment', Journal of Advanced Nursing 21(2), 62-68.

Eustace, R.W. \& Ilagan, P.R., 2010, 'HIV disclosure among HIV positive individuals: A concept analaysis', Journal of Advanced Nursing 66 (9), 2094-2103. PMid:20626492

Falan, S., 2010, 'Concept analysis of Similarity Applied to Nursing Diagnoses: Implications for educators', International Journal of Nursing Terminologies and Classification 21 (4), 144-155. http://dx.doi.org/10.1111/j.1744618X.2010.01163.x, PMid:20977619

Guba E.G. \& Lincoln, Y.S., 1985, Criteria for assessing trustworthiness of naturalistic inquiry. Sage Publications, Thousand Oaks.

Hutchfield, K., 1999, 'Family-centred Care: A concept analysis', Journal of Advanced Nursing 29(5), 90-95. http://dx.doi.org/10.1046/j.1365-2648.1999.00987.x, PMid:10320502

Johnson, M., Stewart, H., Langdon, R., Kelly, P. \& Yong, L., 2003, Woman-centred care and caseload models of midwifery', Collegian 10(1), 30-34. http://dx.doi. org/10.1016/S1322-7696(08)60618-6

Malusky, S.K., 2005, 'A concept analysis of family-centered care in the NICU', Neonata Network 24(6), 25-32. http://dx.doi.org/10.1891/0730-0832.24.6.25

Maputle, M.S. \& Hiss, D.C., 2010, 'Experiences of midwives managing women during labour at a tertiary care hospital in the Limpopo Province', Curationis 33(3), 5-14. 
Maputle, M.S. \& Nolte, A.W.G., 2008, 'Mothers' experience of labour in a tertiary care hospital', Health SA Gesondheid, 13(1), 55-62. http://dx.doi.org/10.4102/hsag. v13i1.257

Mentro, A.M., Steward, D.K. \& Garvin, B.J., 2002, 'Infant feeding responsiveness: A concept analysis', Journal of Advanced Nursing 37(2), 25-40. http://dx.doi. org/10.1046/j.1365-2648.2002.02068.x, PMid:11851789

Midmer, D.K., 1992, 'Does family-centered maternity care empower women? The development of the woman-centered childbirth model', Family Medicine 24(3), 216-221. PMid:1577215

Mikkelsen, G. \& Frederiksen, K., 2011, 'Family-centred care of children in hospital - a concept analysis', Journal of Advanced Nursing 67(5), 1152-1162. http://dx.doi. org/10.1111/j.1365-2648.2010.05574.x, PMid:21272055

Pearson, A., Vaughan, B. \& Fitzgerald, M., 1998, Nursing Models for Practice, Melbourne, Johannesburg, Butterworth-Heinemann. http://dx.doi.org/10.1046 /j.1365-2648.1998.00765.xPMid:9687126

Pelkonen, M., Perala, M.L. \& Vehvilainen-Julknnen, K., 1998, 'Participation of expectant mothers in decision-making in maternity care: results of a populationbased survey', Journal of Advanced Nursing 28(1), 21-29.

Ritcher, D.L., Greaney, M.L., Mckeown, R.E., Cornell, C.E., Littleton, M.A. \& Pulley, L., 2001, 'Developing a video intervention to model effective patient-physician communication and health-related decision-making skills for a multi-ethnic audience', JAMWA 56(4), 174-176. PMid:11759786
Rodgers, B.L., 1993, 'Concept analysis: An Evolutionary view', in B.L. Rodgers \& K.A. Knafl (eds.), Concept development in Nursing: Foundation, Techniques and Application. W.B. Saunders, Philadelphia.

Sandall, J., 1995, 'Choice, continuity and control: Changing Midwifery Towards a Social Perspective', Midwifery 11, 201-209. http://dx.doi.org/10.1016/02666138(95)90005-5

Sun, Y. \& Knobf, M.T., 2008, 'Concept analysis of symptom disclosure in the context of cancer', ANS Adv Nursing Sci. 31, 332-341. PMid:19033748

Tofthagen, R. \& Fagerstrom, L.M., 2010, 'Rodgers' evolutionary concept analysis - a valid method for developing knowledge in nursing science', Scandanivian Journal of Caring Science 24, 21-31. http://dx.doi.org/10.1111/j.14716712.2010.00845.x, PMid:21070310

Unsworth, J., 2000, 'Practice development: A concept analysis', Journal of Advanced Nursing 8(6), 80-84.

Walker, L.O. \& Avant, K.C., 1995, Strategies for theory construction in nursing, Appleton \& Lange, Norwalk (USA).

Walker, L.O. \& Avant, K.C., 2005, Strategies for theory construction in nursing, 4th edn., Pearson Prentice Hall, Upper Saddle River, New Jersey.

Walker, L.O. \& Avant, K.C., 2011, Strategies for theory construction in nursing, 5th edn., Pearson Education, Upper Saddle River, New Jersey. 